\title{
HANDO RUNNEL JA KEELEUUENDUS
}

\author{
ILMAR VENE
}

$\mathrm{V}$

ahekord keeleuuendusega kuulub kõige ärgitavamate küsitavuste hulka, mida Hando Runneli esseistika võib kergitada. Mispärast autor, kes kaldub oma luulet tõlgitamatuks ja ainult eestlastele määratuks pidama, kohtleb nii vaoshoitult inimesi, kes kogu oma elu pühendasid valdavalt eesti keele võimaluste avardamisele? Me ju teame, et kõigist asjust vähem tahaks luuletaja sarnaneda kultuuritoojatega, kelle tegevust on Valmar Adams mälestanud värsiridadega: „Jällenägemist Aaviku sõnadega / tervitan siiralt” (Adams 1971: 105). Küll pole Runnelil mõttes olnud seda või toda keelendit põlu alla panna, kuid juba see, kuidas luuletaja on Aavikust rääkinud, näitlikustab tema suhtumist piisavalt. „Insenerliku uusaja monumentaalsuse üks silmapaistvamaid pioneere eestlaste hulgas oli „keeleuuendaja” Johannes Aavik. Masinaleiutajaliku otsustavusega hakkas ta eesti keele tõulisest ollusest, n-ö puudulikust ja suisa vigasest rahvakeelest looma insenerlikku suurhoonet - eesti õigeimat kirjakeelt" (Runnel 1998: 329).

Leidub ka üks otsesõnaline eksprompt, mille on talletanud luuletajat kõrgelt hindav austaja: „Luule on emakeele võimalus, mõeldav ainult selles keeles. Murdekeel on ühe rahva emakeelne väljendus, on kõige loomulikum keele eluavaldus. Suure hoobi andis emakeelele keeleuuendusliikumine - hakati keelt masindama. See vaesestab kogu keelt tervikuna. Keel saab kultiveerituks, aga on vaene, nagu suured kultuurpõllud. Eesti keele ühiskond on nii väike, et paar-kolm keelediktaatorit võib oma idee peale suruda, nagu tehakse majanduses" (Kamberg 1999: 100).

Talletuse autentsuses pole kahtlust; jutt käib ometi nähtusest, mille ühene hindamine eeldab suurt enesekindlust ja iseteadvust. Ainult Hando Runnel, mõtlejana silmahakkavalt iseseisev, sai keeleuuenduses „suure hoobi” ära tunda. Ühtaegu tundub, et võrdlus suurte kultuurpõldudega ei mõju veenvalt, sest milles muus saaks kultiveerimine seisneda kui mitte parema selekteerimises ja kehvemate keelendite põlustamises? Vaesestamine on viljelemisest lahutamatu. Kõige kaalukamalt kõlavad ehk „paar-kolm keelediktaatorit”: need ju vihjavad, et autori veendumust mööda peaks keel arenema sunnivabalt ja võimalikult paljude kasutajate ühisloominguna.

Midagi konkreetsemat me noist diktaatoreist kuulda ei saa, küll aga on meil võimalik osutada meeldejäävale miniesseele, milles sõna „siiras” võrreldakse sõnaga „kuldne” ja mida tuleks (vist) võtta tunnustusena Johannes Aavikule (Runnel 2008: 216-217), kuigi ülalpool toodud tsitaadi paistel muutub selline oletus küsitavaks. „Uute sõnade ja vähem tuntud sõnade sõnastiku” teises trükis annab autor „siira” asjus teada: „k u n stlikult loodud sõna, a. 1921 alles e t t e p a n e k ustaadiumis" (Aavik 1921: 6). Nii oli kahekümnendate algul, paarkümmend aastat hiljem kasutas August Annist seda sõna juba pseudonüümina (Siiras 1942).

Kõige mõistatuslikumalt kõlavad tsiteeritud lõigus sõnad „hakati keelt masindama”. Paistab selle poole, et lakoonilist kokkuvõtet tuleks ehk tõesti 
võtta „suure hoobi” olemuse selgitajana, kuid selgusest jääb vajaka. Niipalju ainult jääb kahtlusest väljapoole, et praegusi tõlkemasinaid (isegi mitte „raali”, sõna, mis esimest korda kuulduna pani Aaviku imestama) antud juhul silmas ei peeta. Keele masindamisel näikse olevat tähendus, mis avaneb alles pärast tutvumist kaugemate tagamaadega; see osutub hädavajalikuks, kui oleme lugenud arutlusi, milles luuletaja vaeb inimkeelega seostuvat problemaatikat. Keel kuulub kord nähtuste hulka, mis on meis hämmingut põhjustanud juba aastatuhandeid tagasi, ja järelkajad sellest pole kadunud tänini. Ka praegu, kirjutas XX sajandil prantsuse lingvist André Martinet, on isegi haritud ringkonnis sama hästi kui tundmatu, et lisaks kooligrammatikale ja küsimustele „õigest” või „väärast” kõnelemisviisist tegeldakse veel ka keeleteaduse kui sellisega (Martinet 1963: 14). Kuidas sai ta niimoodi kirjutada, kui juba XIX aastasajal ilmusid monograafiad, milles esitati ülevaateid keeleteaduse arengust vanaajal? H. Steinthali raamat kannab koguni pealkirja: „Keeleteaduse (Sprachwissenschaft) ajalugu Kreekas ja Roomas”. Millega seletada, et tervete aastatuhandete möödudes pole kujutlus keeleteadusest ikka veel üldkäibivaks muutunud?

Eks ikka sellega, et ammuaegsetes ühiskondades ei s a n ud ilmuda isegi keeleelu selle mõiste praeguses tähenduses, kõnelemata juba keelet e a d u s e s t. Nüüdisaegse keeleelu ilmumiseks on tarvis kaht peatingimust: kõigepealt oskust keelelisi tooteid hõlpsalt paljundada, tänu millele trükised muutuvad kogu riigis kättesaadavaks, ja seejärel tsentralisatsiooni, mis ülendaks paljundatu seadusandliku tähendusega dokumendiks. Viimasena esitatud tingimuse tarvidus selgub Saksamaa kõrvutamisel Prantsusmaaga. Kellelegi pole saladuseks, kui tõhusalt Prantsuse eeskuju naaberriigis toimis, kuid ühes väga olulises asjas, nimelt keele normeerimises, ei saadud killustatud Saksamaal eeskuju järgida: ortograafiat ühtlustava sõnaraamatuni, mille esimesed trükid ilmusid Prantsusmaal XVII sajandil, jõuti Saksamaal alles pärast ühinemist.

Vähemasti oletuse korras tohiksime toodud põhjuse eluõiguslikuks tunnistada: pisiriigid tõendavad oma iseseisvust esmajoones sellega, et tunnistavad üksnes iseendalt pärinevaid seadusi. Et nähtus pole kadunud ka praeguse globaliseerumise oludes, näitlikustab ABC. Kõigis Euroopa riikides kasutatakse ladina tähestikku, kuid kirjatähtede ühesuguse järjestamiseni ei jõuta vist eales.

Rooma impeerium oli väga tsentraliseeritud ja selle aladel hargnes teedevõrk, millele tollases maailmas ei leidunud võrdset, kuid kirjasõna paljundati seal eraviisiliselt ja sel puhul on autoriteetide rohkus ootuspärane kaasnähtus. Seesama käib ka keskaegsete skriptooriumide kohta. Kui kloostris tegutses redaktor, siis ootuspäraselt pidas ta end parimaks asjatundjaks ja teistel jäi vaid tema autoriteedile alluda. Niisiis olenes kirjutamisviis ajast ja kohast. Esimene seadusandlikult ühtlustatud kirjakeel ilmus tsentralis e e rit u d Prantsusmaal.

Sellest, mida me praegu peame keeleelu normeerimiseks, esines antiiksetes oludes kõigest algeid: autoreile, kes oleksid tahtnud kirjutada õigesti, anti üldist laadi juhiseid. Ja mõistagi panid terasema kuulmisega inimesed tähele, et sama keelt kõneldes võidakse sõnu erinevalt hääldada. Tulnukad kaugest Ibeeriast ei rääkinud tõeliste roomlaste kombel ja selle üle visati nalja.

Aga kui nõnda, siis millega seletada „keeleteaduse ajalugude” ilmumist? Põhjus seisneb selles, et keele kasutamisel rajaneb kogu vaimuelu. Kuidas 
saanuksid Platon ja Aristoteles keeleküsimusi täielikult kõrvale jätta, kui nad olid huvitatud keeleliste vahenditega esitatud otsuste paikapidavusest? Antiikne mõte jõudis mitte ainult loogikani, vaid koguni keelekriitikani: „Lendav nool püsib paigal!" Sellele lisaks täheldati, et iidsete kirjamälestiste lugemisel kerkib alatasa küsitavusi. Eriti tõhusalt aga aitas keeleelu edendada poliitiline kõne, hulkade mõjutamise peavahend antiikajal: hilisantiiksetes oludes üleneb retoorika universaalseks, teisi teadusi koondavaks kunstiks. Kõik see kokku tähendab, et tähelepanekuid, milles keelt puudutatakse kaudsemalt, pakub antiikne vaimuvara õige rikkalikult; soovib keegi mahukaid ülevaateid kirjutada, siis materjalist puudu ei tule.

Eriline koht kuulub kõnealuses mitmekesisuses filoloogiale, st kõrgendatud huvile sõnade tähendusvälja muutumise vastu. „Filoloogia” oleks kohaseim tähis tegevusele, mida me praegu tavatseme võtta keeleteadusena vana-ajal. Lingvistikani, huvini keele kui sellise vastu tollal ei jõutud. Levikujutlust järgides tuleks küll möönda, et haripunkti saavutas ammune keeleteadus muistses Indias, kuid ühtaegu vääriksid meenutamist tollase huvi ajendajad - veedad, mille keel oli üha arusaamatumaks muutunud. Analoogse tarviduse ajel võrsus araabia keeleteadus: sajandite möödudes hakati täheldama, et jumaliku ilmutuse väljendused, millest Koraan koosneb, kõlavad üha mõistatuslikumalt ja see sundis huvituma nende sõnastamisviisist. Kreekas ei tuntud kanoniseeritud pühatekste, kuid seal, olgugi ametliku pühitsuseta, käibisid jumaliku maailma kajastustena Homerose eeposed ja nendegi keel oli juba klassikalisel ajajärgul raskesti mõistetav. Vajadusest muuta ammused vaimuväärtused üldisemalt arusaadavaiks tuleneb Aleksandria grammatikute tegevus.

„Filoloogia” ja „lingvistika” on kaks koondtähist, mille alla mahub igasugune keeleküsimustele suunduv huvi. Ületamatu eraldusjoonega neid lahutada ei saa, kuid üldjoontes osutuvad erinevused õige rahuldavalt piiritletavaiks. Filoloogia kutsub ellu praktilist laadi tarvidus, st soov selgitada lähemalt nähtamatut tähendust, mida kirjutaja on nähtavate märkide kaudu väljendanud. Lingvisti huvi seevastu suundub esmajoones nähtavale välisusele, sellele, kuidas keel iseendasse sulguva süsteemina oma otstarvet täidab; tähtis pole niivõrd üksiksõnade tähendus, kuivõrd see, kuidas iga osake toimib terviklikus süsteemis. Pent Nurmekund näiteks, olles väitekirja aineks valinud vanaprantsuse lühieepose, saanuks elu lõpuni selgitada, kuidas kajastub tolles teoses keskaegne ühiskond, kuid paraku laskis noor uurija end juhtida mitte filoloogilist, vaid lingvistilist laadi huvist: tema tähelepanu kuulus esmajoones ühele eessõnadest, täpsemalt sellele, missuguseid funktsioone too eessõna kirjamälestises täidab.

Keelehuvilisena oli meie tuntuim polüglott läbinisti lingvist: uue keele õppimist alustades keskendus ta foneetikale, et seejärel võtta käsile grammatika, mis tuli tingimata omandada põhjalikult. Filoloogilise suunitlusega huvilisele ehk tundub, et grammatikat saab tuletada alles keelelisest tervikust, sellal kui lingvisti meelest tuleb alustada just grammatikast: Ferdinand Johann Wiedemann teadis, missuguseid küsimusi keelejuhtidele esitada, et keelelist teljestikku kätte saada. Lingvistiline huvisuunitlus toimib määravana juba eestikeelse uurimistöö algusaegadel. Küll üritas Jakob Hurt sõnadest ka nähtamatuid vaimuväärtusi esile tuua (üks ettekanne kannab isegi pealkirja „Eesti astronoomia”), kuid autori eelistus kuulus nähtava ainese kor- 
raldamisele. Sest mis parata, pretendeerib uurija teaduslikkusele, siis tema mõtestamistöö peab rajanema nähtavail tõendeil: oletuslikku laadi tuletamine arvatakse esseistikaks. Igaüks, kes pisutki huvitunud arheoloogiast, on tuttav kurva paratamatusega: leidude täpne kirjeldus püsib range teaduslikkuse raames, kuid seda pole huvitav lugeda; võtab teadur leidudest kujutluspilte tuletada, siis tema jutt muutub küll huvitavamaks, kuid ühtaegu esseistlikuks. Sama käib ka keelearheoloogia kohta: õnnestub hoogsa mõttelennuga inimesel üksikuist sõnust midagi huvitavat välja lugeda, siis paremal juhul leitakse, et „selles on palju problemaatilist”.

Muudele valdkondadele lisaks näitlikustab ilmalikustumise kulgu ka keeleteaduse edenemine; ülevaatlikkuse nimel piirdugem selle esitamisel viie punktiga. Kõigepealt eeldati endastmõistetavuse korras, et inimkeel pärineb Jumalalt. Järgmisena tuli juba, et kõik idioomid on arenenud jumalikust heebrea keelest. Üheksateistkümnendal aastasajal, pärast kõikvõimalike väärkujutluste hääbumist, jõutakse lõpuks ajaloolis-võrdleva keeleteaduseni: keeli võrreldes loodetakse inimajaloo algaegadeni tungida teaduslikul teel. Üldistavalt võiksime seda saavutust pidada keeleteaduse filoloogilise ajastu krooniks ja lõpetuseks; järgnevalt tuleb juba lingvistika, keeleteadus praeguses tähenduses. Ülemineku juhatab sisse teisenenud rõhuasetus: noorgrammatikud tuvastavad, et keele ehedaimaks väljenduseks ei tule pidada kirjamärke, mille vahendusel iidseid kultuurkeeli talletati, vaid üksikinimese suulist kõnet. Keeleteaduse lõppjärgu juhatab sisse Ferdinand de Saussure’i tegevus; vertikaalse süvamõõtme asemele, mille najal hinnati ajaloolis-võrdleva keeleteaduse saavutusi, tuleb horisontaal: uurijate pingutused suunduvad keelelise välisuse, süsteemsuse ja mõistuspäraselt esitatava tervikluse tundmaõppimisele. Küll ei vaibu tung sügavusse jäägitult; tänini esineb huvilisi, kes kõige erinevamaid keeli kõrvutades tahavad aimu saada protokeelest. Eks kuulu mingi eluõigus ka hüpoteesile, mille kohaselt inimsuse areng olevat alguse saanud ainukesest tsivilisatsioonist; ja kui nii tõesti oli, siis peaksid kõik keeled pärinema suhtlemisvahendist, mis kümneid tuhandeid aastaid tagasi liitis Aafrikas elanud inimsoo esindajad sotsiaalseks tervikuks. Muidugi viib see oletus mõtted Paabeli keeltesegadusele ja igavesele ringkäigule: algas kõik „globaalsusest”, siis peab see tulema ka lõpetuseks.

Aga nood protokeelest huvitujad, kes on osutanud, et sõnad, millega märgitakse „vett” ja „piima”, elu jätkumiseks olulisimat, võivad ilmutada sarnasusi kõige erinevamais keelis - nood protokeelest huvitujad kuuluvad eksootiliste erandite hulka. Valdavalt on keelehuvilised pühendunud ühele kahest: semantikale või süsteemsusele, st filoloogiale või lingvistikale. Suundumuse tuvastamiseks piisab selgitamisest, millena võtab huviline sõna, keele algüksust.

Johannes Aavik: „Meie käsitust mööda on sõnale, seks et eestiline olla, kyllalt olla foneetiliselt, kõlaliselt eestitaoline. See tähendab, ta tarvitseb vaid koosneda neist häälikuist ja häälikute yhtumeist, milleks olevad rahvaomased sõnad analoogiaid pakuvad. Ainult se e on oluline. Sõna algu pär a, põ hju s ei ole mitte oluline, vaid on teisväärne, on kõrvalise tähtsusega” (Aavik 1924: 37).

Hando Runnel: „Sõna on aga olemuselt mineviku saadik, sõna on olevikus elav minevik ise" (Runnel 1984a: 33-34).

Tsitaadid näitlikustavad piisavalt, mille poolest erineb lingvistiline huvi filoloogilisest. Esimesel juhul võetakse sõna nähtava märgina ja kõige täht- 
samaks osutub selle kõlaline kooskõla süsteemse terviku muude märkidega, sellal kui vastanduvas vaatekohas esineb sõna nähtamatu vaimu talletajana, vaimuelu kestvuse ning selle uute kandjate kujundamise võimaldajana.

Lähem tutvus kummagi vaateviisi esindajatega tõendab esmase mulje paikapidavust: üha uuesti selgub, et jooni, mis Aaviku silmis tulid arvesse esimestena, pole Runnel üldse maininud. Tapal peetud kõnes („Kellele kuulub keel”- Runnel 1984c) vaetakse nähtust nii-öelda filosoofiliselt tasandilt ja lõpetuseks selgub, et keele alalhoid pole vähemat kui kindlaim tagatis rahva säilimisele. Mõistagi oli eestluse püsimisest ka Aavik huvitatud, kuid tema eelistas oma suhtumist väljendades vähema kandvusega sõnastust. „Ideepest” loeme: „Minule näib ikka, et Eesti rahva saatus oleneb keeleuuendusest ja selle saatusest. Kui Eesti rahvas tahab lõplikolt jääda praeguse halva MuukVeski rõivakeele juure, siis ta ei vääri paremat saatust kui kadoda ja sulada mingisse teise rahvusesse" (Aavik 2010: 117). Ka viimases kirjas Tuglasele ei jäta keeleuuendaja seda veendumust väljendamata (Aavik, Tuglas 1990: 168).

Eriti selgelt näitab suhtumiste vastandlikkust arusaam ajalisusest. Runneli meelest elab keeles minevik, millest veelgi sügavamat me ei tunne. PaulEerik Rummo kohta öeldakse: „Tema luule ei kasva ümbrusest, vaid temast endast või veelgi enam: keelest, milles ta elab - ta on sama vana kui keel, see tähendab ürgne" (Runnel 2008: 171). Pole kahtlust, et tunnustust avaldades on arvustaja viimase välja pannud; oleks talle vaid teada mõni iidsem ürgsus, siis ta toetuks sellele. Aavik seevastu, ajaliste sügavuste suhtes hoolimatu, kaldub eriliselt eelistama hoopis väärtusi, mis on loodud siin ja praegu. Raamatus „Keeleuuenduse äärmised võimalused” tehakse üksipulgi selgeks, et uute juursõnade kunstlik loomine, olgugi esmapilgul kahtlase väärtusega, pole kuidagi välditav. Rahvakeeles, murdeist kõnelemata, kõrgelennulise kõlaga üldmõisteid ei leidu, kuna lihtrahva igapäevane elu jääb subliimsustest kaugele. Soome keelest ei saa alati laenata, kuna mõnelgi juhul teeb selle võimatuks laenu eksitav sarnasus eestikeelsete sõnadega. Kaugematest keeltest pärinevad sõnad ei kõla eestilikult, mistõttu neid tuleb eelnevalt töödelda. Õhin, millega keeleuuendaja kõneleb, ei jäta kahtlust, et tema eriline poolehoid kuulub kunstlikult loodud sõnadele. Kõik teed on välmijale lahti ja segavad kõrvaltegurid puuduvad täielikult. Seda tõendamaks esitab autor konkreetseid näiteid, tutvustades oma tuletamistööd viimsenimineva põhjalikkusega: kõigepealt selgitatakse, missuguseid häälikuid peaks tulevane sõna sisaldama, seejärel moodustatakse kõik iganes võimalikud variandid ja alles lõpetuseks teeb nõudlik selektsioon kindlaks, missugusele nendest peaks kuuluma tingimatu eelistus.

Uuendaja teadis, et juba pretsedentide puudumise pärast ei saa üldsus tema hoiakut soosida ja seepärast ta ei väsinud kordamast: pole tähtis, kas seadeldise on loonud lähisugulane või võhivõõras, arvesse tuleb üksnes otstarbekus. „Kordame veel: keel on riist, keel on masin. Seepärast ei pea tema peale vaatama mitte yksi loodusteadlase silmaga, keda huvitab ainult nähtuse konstateerimine ja seletus, vaid ka tööstusinimese, inseneri, tehniku silmaga, kes nähtusi oma kasuks, oma otstarvete kohaselt püüab painutada ja kasutada" (Aavik 1924: 9).

Oleme jõudnud üheni võtmesõnadest, mis vaatlusaluseid suhtumisi teineteisest lahutab. Runnel, nagu eespool juba osutatud, näeb keeles tagatist rahva kestvusele, sellal kui Aaviku silmis püsib esiplaanil vahend sõnakunsti 
loomiseks. Keelt, sarnaselt muude töövahenditega, tuleb hinnata otstarbekuse ja paindlikkuse mõõdupuuga.

Sellest suurest vahetegemisest johtuvad kitsama kandvusega haruavaldused. Missugusena kujutleda looja vahekorda looduga? Aavikul ilmneb kalduvus toonitada looja primaati; püsib õigsus ja otstarbekus esiplaanil, siis inimesele, kõnealuste väärtuste edendajale, peaks ootuspäraselt juhtseisund kuuluma. Runneli jaoks osutub küsimus üheselt lahendamatuks. Ühelt poolt justkui paistaks, et keelt tuleb oma loojast suuremaks pidada; on ju kõnelejad põrmlikult üürikesed olevused, kes kasinate elupäevade mööda saades jäävad mingil määral elama ainult keeles; see, koondades endasse erinevaid aegu, osutub kõnelejaist ilmselgelt suuremaks. Samas jälle pole ta e n n e kõnelejaid kujuteldav. Nii jõuabki Runnel oma ettekandes „Kellele kuulub keel” kokkuvõtteni: keelt, rahvast ning neid koos hoidvat riiki tuleks võtta kolmainsusena.

Kuid see puhtanisti mõistuspärane apooria ei kaota jooni, mis näivad keelele esimuse tagavat: kolmainsuse esimene liige, olgugi rahva looming, üleneb pärast ilmumist rahva vaimu, niisiis tema tõelise elu talletajaks ning kujuneb sellisena vastukaaluks põrmlikule põgususele. Keel kasvab orgaaniliselt, kuuludes elusolendite hulka, sellal kui masin pole enamat kui inimeselt või inimeste rühmalt pärinev rajatis, mille ainus otstarve seisneb inimelu hõlbustamises; seadeldis, mida enam ei vajata, kaob nii täielikult, et isegi selle nime tähendust ei suudeta tagantjärele mõista. Lugeja, kes Vana Testamendiga lähemalt tuttav, on ehk kuulnud, kui oluline koht kuulub pühakirja arusaamatus leksikas ammuste tööriistade nimetustele.

Pärast neid ettevalmistavaid märkusi peaksime aimama, mida võiks tähendada too võõrastavalt kõlav kokkuvõte, mis ülalpool juba toodud ja millega Hando Runnel on põhjendanud oma tõrjehoiakut keeleuuenduse suhtes: „hakati keelt masindama”. Jutt pole „keelest” ja „masinast” nende päristähenduses, vaid üldisima kandvusega mõisteist, mis liiati teineteisele enam-vähem vastanduvad. Keel on Runneli silmis kõrgeim väärtus ja isegi kõige tõhusama toimega jõud, kuid luuletajal pole mõtteski pidada teda jumaluseks, kõnelemata juba üliväärtuse ülendamisest ainujumala seisundisse. Sest kuidas saaks Keel luua taeva ja maa? Alguses võis Sõna ju olla, aga seda, kuidas ta algusviivudel toimis, me aimata ei suuda.

Veelgi suuremaid mööndusi tuleb teha „masinast” kõneldes. Eituse või koguni kurjuse vaimu avaldumisega pole üldse tegemist; keegi meist ei kahtle, et seadeldiste ainus siht, relvad kaasa arvatud, seisneb heaolu kasvatamises. Kurt Vonnegut imestas: Millega teadlased ka tegeleksid - lõppsaaduseks kujunevad ikka relvad. Aga kuidas saaks olla teisiti, kui rahvuslikku julgeolekut peetakse kõige kõrgemaks väärtuseks?

Õnneks kuulub keele masindamine nähtuste hulka, millel relvastumisega pole vahetuid kokkupuuteid; ja isegi kujutlus keelest kui masinast, nagu Johannes Aaviku tegevus veenab, ei tarvitse alati kahjulik olla. Kes meist vaevuks lobisemise käigus meenutama, et „siiras”, „veenma” ja muud tuletised, mida on leegion, pärinevad Aavikult? Ka Hando Runnel, tohime eeldada, ei hakka neid uuendusi taunima. Keeleuuendajast muigetoonil kõneldes tahab luuletaja ainult osutada, et ülemäärane tahe keele arengut suunata kahjustab suunatava seisundit. On see ikka täisväärtuslik elu, mille liikumine roobastesse juhitakse? Paraku leidub inimesi, kes kõveraks kasvatatud puu arvavad 
ilusamaks sunnivabalt kasvanust. Juba sajandeid tagasi vaieldi, kumba pidada ilusamaks: Prantsuse või Inglise parki?

Masina suhteline vastandumine keelele, millel Hando Runneli mõtlemisviis rajaneb, muutub rahuldavalt arusaadavaks alles pärast lähemat tutvumist vastandeid võrsutanud olustikuga. Ilmalikkus on kõnealuse vastandite paari esile toonud, et arhailine vastasseis (jumal contra kurat) saaks uusaegse asenduse; järelikult tuleb kõigepealt selgitada, milles väljendub sekulaarsus ennekõike. Ilmalikkus jaotub kaheselt: vulgaarseks ja mõõdukaks. Vulgaarne ilmalikkus, nagu nimigi juba ütleb, toimib üldvalitsevana ja selle olemus mahub kahte teesi: 1) inimene kõlab uhkelt; 2) kristlus on inimvaenulik.

Kõike need teesid muidugi ei hõlma; jääb näiteks selgitamata, milles kristluse inimvaenulikkus väljendub. Väljendub see aga suurema tõeläheduse taotlemises; kristlus tunnistab avalikult, et inimene o $\mathrm{n}$ halb. Loomisele järgnenud ajal puudulikkust veel polnud, kuid paraku tegi pärispatt inimloomuse algsele terviklusele lõpu ja alles Kristuse tegevus lunastajana andis lihtsurelikele tagasi võimaluse algse tervikluseni jõuda. Pärispatt nimelt on inimloomuse algset täiust küll moonutanud, kuid loomuse jumalik päritolu ei läinud seeläbi kaotsi. Ja sellest tuleneb üldjoontes optimistlik kokkuvõte: teeb lihtsurelik oma parima, et endasse kätketud jumalikkuse kübet võimendada, siis sellega korvatakse pärispatuga kaasunud moondumus.

Uusaegses olustikus alaneb selline kujutlus mütoloogia tasandile. Keskaegse pimediku hüljanud sajandid kujundavad aegamööda lihtsureliku, kes üle kõige hindab mõistuspärasust ja seepärast leitakse arhailiselt ülemõistuslikele kujutlusile arusaadavad põhjendused. Pärispatu asemel hakkab määrav seisund kuuluma eraomandile ja isevusele (s.o egoismile): viimane peibutab lihtsurelikke esimest kasvatama. Isegi tuimaloomulise talurahva esindajail tuleb igapäevases elus täheldada, kuidas loomad omavahel toidu pärast kisklevad, ja sedalaadi tähelepanekud viivad mõttele, et teisiti pole ka inimühiskonnas. Juba XVII aastasajal esitab Gracian jesuiitlikult kavala põhjenduse: Jumal lõi inimese loomadega nii sarnaseks sellepärast, et inimest ja tema usku proovile panna. Samal sajandil saab see tarkus Hobbes'ilt olulise täienduse: inimloomus on moondunud nii rängalt, et lihtsurelike kooselu laabub ainult riigi, Leviaatani suunavale sunnile alludes. Veel pole riik mandunud elutuks masinaks; kuulub ju Leviaatan, välisele eemaletõukavusele vaatamata, elusolendite hulka. Aga kujutlused ei püsi muutumatud: Jean-Jacques Rousseau, valgustusajastu tippmõtleja, usub juba inimese ahvilikku päritolu ja sadakond aastat pärast teda tuleb Karl Marx välja võõrandumise mõistega. Marxil oli eriline anne anda triviaalsustele sõnastusi, mis kõlavad mõistuspäraselt ja ühtaegu seletamatuseni sügavalt. „Võõrandumine”, tõendeist üks kuulsamaid, tahab öelda, et inimlik „looming”, millega lihtsurelik püüab oma eksistentsi kindlustada, pöördub vaenulikkuseni võõ r a n a tema vastu. Antiikajal olid kõlbluse jutlustajad piirdunud keelitamisega: mida ohtramalt varandust, seda arvukamalt muresid; targa siht aga peaks seisnema võimalikult suurema sõltumatuse saavutamises. Ristiusk teravdas selle nõude äärmuseni: sina pead oma ligimest küll armastama, aga sa ei tohi temasse kiinduda, kuna Jumal võib sind temast iga hetk ilma jätta ja siis sinul, arutult elanul, tuleb taluda mõttetuid kannatusi. Kiindumus tohib sind siduda ainult Jumala, nähtamatu ideega; see on ainus kirg, mis sulle alati ainult annab, sinult vähimatki võtmata. 
Kahjuks ei toiminud need ilusad õpetussõnad piisavalt; moondunud loomuga lihtsurelik jätkas ahnitsemist, mistõttu omandisuhted komplitseerusid sedavõrd, et nendele saadi püsi tagada ainult riiklikult, st seadusandlikus korras. Riigimasin, mille lihtsurelikud loonud, hakkab oma loojaid ahistama. Aastatuhandeid jätkunud väärarengu saab kokku võtta vormeliga: ebaõiglane ühiskond on inimloomust moonutanud nii rängalt, et inimene oma algset jumalikkust isegi mitte ei mäleta.

Nii ebaloomulik olukord ei tohtinud kesta igavesti. XIX sajandil jõutakse veendumusele, et ühiskond, mille liikmed on endile võõraks muutunud, peab taas inimnäoliseks ülenema. Või otsesõnu: inimloomus pidi algse jumalikkuse tagasi saama. Anarhistlik meelestatus muutub üldiseks: elutule ja ebainimlikule riigim a s in a le, mille inimvaenulik kristlus võrsutanud, soovitakse kadu. Samas tuleb möönda, et anarhismi tollased eestkõnelejad (Pjotr Kropotkin, Lev Tolstoi, Mihhail Bakunin ja Karl Marx) võisid üksikküsimuste lahendamisel ka erimeelsust ilmutada; iseäranis ilmnevad erinevused religioosse värvinguga asjus. Kropotkin ja Tolstoi mõjuvad otsekui religioosse meelsuse koondkehastused; nende meelest piisab kõigi raskuste kaotamiseks ainult ühest: elutu riigimasina, kogu kurja juure hävitamisest. Kohe pärast seda, tundus mõtlejaile, paneb inimloomuse jumalikkus end maksma ja ühiskond muutub inimväärseks. Bakunin koguni jättis edasise ondsuse täiesti tuleviku asjaks, hoolides esmajoones purustamisest; oli ju lammutamine tema meelest l o o v tegevus. Marx, tuntud „radikaalhumanist” (Erich Fromm), mõtles kõige järjekindlamalt, kujutledes jumalikkuse ennistamist kolmesena. Kõigepealt tuli ebaõiglane ja võõrandumist põhjustav riigimasin purustada. Järgnevalt pidi selle asemele tulema uus ja õiglane riigiaparaat, inimloomuse jumalikkuse ennistaja ning alles pärast üleminekuaega, proletariaadi diktatuuri, mille toimides „võõrandumine” kaob, tohtis ühiskonna areng jätkuda isevoolu, st anarhiliselt, õigluse arhontide suuniseid vajamata.

Sellisena ilmuks visandlik eellugu, kui tahaksime paremini mõista, mispärast on m a s i n Hando Runneli mõtlemises nii oluliseks kujunenud; oleme vastamisi suurmõistega, mis ilmalikustumise käigus ilmub möödapääsmatult. Sekulariseerumisega kaasuv problemaatika aga moodustab just põhilise, mille mõtestamisega on luuletaja juba poole sajandi vältel tegelnud. „Kui me poleks INIMESEUSKLIKUD," öeldakse Tammsaare suurjuubelit tähistavas lühiessees (Runnel 1984b: 35); siis kõiki neid kitsaskohti, mida inimülesuse mittetunnistamine põhjustab, üldse ei paistaks. Paraku pole üldsuhtumised meie teha; ja seepärast „me usume inimest ja usume inimese vaimu” (Runnel 1984b: 35). Kõnealusel usul on kaks suurkomponenti: esiteks soovime inimtunnetust kujutleda kõikvõimsana ja teiseks elab meis kalduvus tunnistada inimese loomupärast headust. (Kuulus vormel „inimene on loomult hea” tähendab, et pärispatt pole inimloomust moonutanud.) Igapäevasemal kujul väljendub ilmalikustumine kalduvuses leida inimlikele puudustele pehmendavaid asjaolusid. Põhilistele nendest oleme ennist osutanud: inimest rikub ebaõiglane keskkond (raske lapsepõlv), ebainimlik riigimasin, olgugi inimese enda loodud jne. Kõnealusest kalduvusest, endastki mõista, pole täielikult vaba ka Hando Runnel. Ülalpool on vilksatanud ilmalikkuse jaotumine vulgaarseks ja mõõdukaks; võiksime lisada, et esineb ka vanameelseid ilmikuid. Sest mille muu kui mitte kristliku meelsuse esindusnäidistena peaksime võtma luuletaja üliväärtusi? Kõlbluse primaat ja maailma võitmine headusele kuuluvad kindlalt 
kristliku raudvara hulka. Aga Runneli vanameelsust võib täiendada ka ilmalikuma varjundiga kristlus. Meenutagem, mida öeldakse kõnes „Hingerahust ja bürokraatiamasina kohutavusest”: „Meie konflikt näiteks Rein Ristlaanega ei ole inimese konflikt inimesega, vaid olemuselt just nimelt seesama looduse konflikt masinaga või: loodusliku konflikt masinalisega” (Runnel 1991: 36).

Looduslikkuse kõrgeimaks väljenduseks osutub Keel, elus üliväärtus, kes areneb seda täisväärtuslikumalt, mida ettevaatlikum ollakse tema sundimisel ja suunamisel. „Masinalise” otstarve aga seisneb just suunamises ja sundimises; ja seepärast luuletajale tundub, et poleks ülearu, kui me oma rõõmu masinalistest saavutustest täiendaksime mõningase umbusuga. Hando Runnel on INIMESEUSKLIK.

\section{Kirjandus}

Aavik 1921 = Uute sõnade ja vähem tuntud sõnade sõnastik. Sisaldab yle 4000 uuema ja vähem tuntud ning haruldasema sõna. Kokku säädnud Joh. Aavik. Teine parandet ja suuresti täiendet trykk. Tallinn: A. Keisermann.

A a vi k, Johannes 1924. Keeleuuenduse äärmised võimalused. Tartu: Istandik.

A a vi k, Johannes 2010. Ideepe. Johannes Aaviku ideede päevik. Väljaande koostaja ja peatoimetaja Helgi Vihma. Tallinn: TEA kirjastus.

Aavik, Tuglas 1990 = Kultuurilugu kirjapeeglis. Johannes Aaviku ja Friedebert Tuglase kirjavahetus. Koostanud ja kommenteerinud Helgi Vihma. Tallinn: Eesti Raamat.

A d a m s, Valmar 1971. Sinu sekundid. Tallinn: Eesti Raamat.

K a m b e r g, Erik 1999. Tartus-viibija käekõrval. - Läbi äreva vere. Pühendusteos Hando Runnelile. Tartu: HRS, lk 87-110.

M a r ti n et, André 1963. Grundzüge der Allgemeinen Sprachwisseschaft. Stuttgart: Kohlhammer.

R u n n e 1, Hando 1984a. Mütoloogiatest. - Hando Runnel, Ei hõbedat, kulda. Tallinn: Eesti Raamat, lk 31-34.

R u n n e l, Hando 1984b. Aja lugu. - Hando Runnel, Ei hõbedat, kulda. Tallinn: Eesti Raamat, lk 34-35.

R u n n e 1, Hando 1984c. Kellele kuulub keel. (Kõne Tapa keelepäeval). - Hando Runnel, Ei hõbedat, kulda. Tallinn: Eesti Raamat, lk 261-267.

R u n n e l, Hando 1991. Hingerahust ja bürokraatiamasina kohutavusest. (Kirjanike kongressil 1986). - Hando Runnel, Isamaavajadus. Tallinn: Perioodika, lk 36.

R u n ne 1, Hando 1998. Kuidas Poe Edgar Adamsoni Hendriku vangi võttis. Hando Runnel, Jooksu pealt suudeldud. Tartu: Ilmamaa, lk 326-340.

R u n n e 1, Hando 2008. Väravahingede kriiksumist kuulnud ehk mõisteline sõnastik autori elu- ja loominguloo juurde. Tartu: Ilmamaa.

S i i r a s, Jaan 1942. Viro neuvostokurimuksessa: piirteitä Viron tapahtumista ja kehityksestä bolševikkivallan aikana vv. 1939-1941. Porvoo-Helsinki: WSOY. 